\title{
Incidence of coronary bifurcation lesion as a culprit lesion in patients with acute myocardial infarction: impact of treatment strategy on short- and long-term outcomes
}

\author{
DHazar Harbalioglu*, \\ DCaner Turkoglu², \\ DTaner Seker ${ }^{3}$, \\ DAlaa Quisi ${ }^{4}$, \\ (D) Omer Genc ${ }^{3}$, \\ Dokhan Alici5, \\ Samir Allahverdiyev ${ }^{6}$, \\ DAhmet Oytun \\ Baykan $^{3}$, \\ (D) Mustafa Gur ${ }^{3}$
}

'Duzce Ataturk State Hospital, Department of Cardiology, Duzce, Turkey

${ }^{2}$ Malatya Research and Training Hospital, Department of Cardiology, Malatya/Turkey

${ }^{3}$ Universtiy of Health Sciences Adana Health Practices and Research Center, Department of Cardiology, Adana/Turkey

${ }^{4}$ Department of Cardiology, Medline Adana Hospital, Adana, Turkey

${ }^{5}$ Okmeydani Research and Training Hospital, Department of Cardiology, Istanbul/Turkey

${ }^{6}$ Department of Cardiology, Biruni University Faculty of Medicine, İstanbul, Turkey

RECEIVED:

June 25, 2019

ACCEPTED:

September 16, 2019

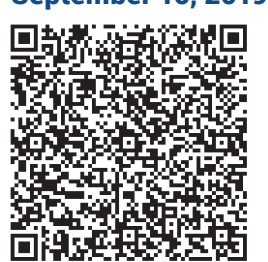

KEYWORDS: acute coronary syndrome, bifurcation, revascularization, side branch loss, mortality. CITATION: Cardiol Croat. 2019;14(9-10):209. | https://doi.org/10.15836/ccar2019.209

*ADDRESS FOR CORRESPONDENCE: Hazar Harbalioglu, Duzce Ataturk State Hospital, Department of Cardiology, Duzce, Turkey. / Phone: +905363602980 / E-mail: hazarhmail@hotmail.com

ORCID: Hazar Harbalioglu, https://orcid.org/0000-0002-6694-814X • Caner Turkoglu, https://orcid.org/0000-0003-1275-630X Taner Seker, https://orcid.org/0000-0003-4254-907X • Alaa Quisi, https://orcid.org/0000-0002-5862-5789

Omer Genc, https://orcid.org/0000-0002-9097-5391 • Gokhan Alici, https://orcid.org/0000-0002-4589-7566

Samir Allahverdiyev, https://orcid.org/0000-0003-3175-0835 • Ahmet Oytun Baykan, https://orcid.org/0000-0002-6103-2511

Mustafa Gur, https://orcid.org/0000-0002-2474-5352

IIIIIIIIIIIIIIIIIIIIIIIIIIIIIIIIIIIIIIIIIIIIIIIIIIIIIIIIIIIIIIIIIIIIIIIIIIIIIIIIIIIIIIIIIIIIIIIIIIIIIIIIIIIIIIIIIIIIIII

Background: Although, there are several studies comparing single and two-stent techniques in patients with bifurcation lesions, evidence in patients presenting with myocardial infarction (MI) is still insufficient. ${ }^{-3}$ We aimed to assess the short- and long-term outcomes of provisional and two-stent techniques of bifurcation lesions in patients with acute coronary syndromes (ACS).

Patients and Methods: 2992 patients with MI who underwent percutaneous coronary intervention (PCI) were enrolled in the present study. Of 2992 patients, 385 patients with MI had bifurcation lesions. The Synergy between PCI with TAXUS ${ }^{\text {TM }}$ and Cardiac Surgery (SYNTAX) score, pre-PCI Thrombolysis in Myocardial Infarction (TIMI) flow, post-PCI TIMI flow, duration of procedure, angiographic features, post-PCI side branch loss, 1- and 12-month mortality rates were noted.

Results: 169 (43.9\%) patients had ST-segment elevation MI, whereas 216 (56.1\%) patients had non-STsegment elevation MI. 355 (92.2\%) patients underwent provisional stenting and 30 (7.8\%) patients underwent two-stent technique. Side branch loss was observed in 40 patients (11.2\%) in the provisional group and 1 patient $(3.3 \%)$ in the two-stent group $(\mathrm{p}=0.2)$. Compared to provisional group, durations of angiography and revascularization in two-stent group were significantly longer $(p<0.001$ and $p<0.001)$ Both 1-month and 12-month mortality rates were similar in provisional and two-stent groups (4.2\% vs. $3.3 \%, p=0.8$ and $11.5 \%$ and $13.3 \%, p=0.7$; respectively)

Conclusion: In patients presenting with ACS and bifurcation lesions, procedural success, side branch loss, as well as short- and long-term mortality were similar in both provisional and two-stent techniques.

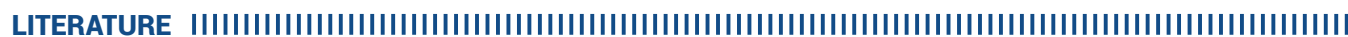

1. Falk E, Shah PK, Fuster V. Coronary plaque disruption. Circulation. 1995 Aug 1;92(3):657-71. https://doi.org/10.1161/01.cir.92.3.657

2. Ross R. Atherosclerosis--an inflammatory disease. N Engl J Med. 1999 Jan 14;340(2):115-26. https://doi.org/10.1056/NEJM199901143400207

3. Fuster V, Badimon L, Badimon JJ, Chesebro JH. The pathogenesis of coronary artery disease and acute coronary syndromes. N Engl J Med. 1992 Jan 23;326(4):242-50. https://doi.org/10.1056/NEJM199201233260406 